\title{
Probing into farmers' perceptions of a globally endangered ecosystem service provider
}

\author{
Marina García-Alfonso (i), Zebensui Morales-Reyes, Laura Gangoso, \\ Willem Bouten, José A. Sánchez-Zapata, David Serrano, \\ José A. Donázar
}

Received: 9 November 2017/Revised: 16 July 2018/Accepted: 10 September 2018/Published online: 22 September 2018

\begin{abstract}
Society's perception of ecosystem services is a key issue in conservation, particularly for endangered species providing services linked to human activities. Misperceptions may lead to wildlife-human conflicts with the risk of disappearance of the species involved. We contrasted farmers' perceptions with highly accurate quantitative data of an endangered vulture species, which provide ecosystem services. We combined surveys of 59 farmers with data from 48 GPS-tagged Canarian Egyptian vultures (Neophron percnopterus majorensis endemic to the Spanish Canary Islands) to disentangle factors influencing consistency between farmers' awareness of vulture occurrence on their properties and vulture behavior. Egyptian vultures were perceived as the main providers of scavenging services and the most beneficial avian scavenger. Consistency between farmers' perceptions (surveys) and vulture use of their farms (GPS data) was higher in the morning, in older males, and at farms with lower livestock numbers, located near vulture communal roosts, and visited more frequently by vultures. Our results underline the potential influence of modern livestock husbandry in disconnecting people from ecosystems, and how appreciation could be even lower for scarce or threatened ecosystem service providers.
\end{abstract}

Keywords Biodiversity conservation - Canary Islands . Egyptian vultures - GPS tracking ·

Local ecological knowledge $\cdot$ Social perception

Electronic supplementary material The online version of this article (https://doi.org/10.1007/s13280-018-1102-3) contains supplementary material, which is available to authorized users.

\section{INTRODUCTION}

The importance of maintaining biodiversity to support the provision of ecosystem services and its relation to human well-being is broadly recognized (e.g., MA 2005; Díaz et al. 2015). Ecosystem services are defined as the benefits that people obtain from ecosystems (Díaz et al. 2015) and include provisioning (e.g., food and water), regulating (e.g., climate regulation, water purification or disease and pest control), and cultural services (e.g., recreation, reflection, cognitive development). Research on ecosystem services has focused on quantifying biophysical or economic value (Martín-López et al. 2012; de Oliveira and Berkes 2014; Martín-López and Montes 2015; Sekercioglu et al. 2016), but increasing attention is being paid to efficiency, the interrelationships with human activities, and the role played by populations or species delivering the service-the so-called "ecosystem service providers" (Kremen 2005; MA 2005; Whelan et al. 2008; Luck et al. 2009; Moleón et al. 2014).

The importance of maintaining ecosystem services from a socioecological perspective has not been recognized until very recently (Martín-López and Montes 2015; Bennett et al. 2016). Bearing in mind that humans are a crucial piece of many ecosystems, the need to avoid the disconnection of ecosystems from human societies is acknowledged (Cowling et al. 2008; Olea and Mateo-Tomás 2009; Martín-López and Montes 2015; Bennett et al. 2016). Consequently, society's perception of ecosystem services is a key issue for conservation (Morgan-Brown et al. 2010; Ban et al. 2013).

Most studies on society's perception of ecosystem services have focused on coarse approximations of their recognition and relative importance, knowledge of the concept of ecosystem services, and the personal features 
determining differences in perception between individuals (Lewan and Söderqvist 2002; Martín-López et al. 2012; Hartter et al. 2014; Muhamad et al. 2014). Less attention has been devoted to the appreciation of the ecosystem service providers (ESPs; Pfeiffer et al. 2015). This is not a trivial issue because a misperception about the role of organisms interacting with stakeholders may determine the emergence of wildlife-human conflicts (Everard et al. 2017) with the subsequent risk of disappearance of the organisms providing such services (Allen 1893).

Obligate (i.e., vultures) and facultative (e.g., corvids, mammalian carnivores, or raptors) scavengers provide crucial regulating services through carcass removal, such as nutrient cycling and disease and pest control (Whelan et al. 2008; Wilson and Wolkovich 2011; Ogada et al. 2012; Moleón et al. 2014; Morales-Reyes et al. 2015; Sekercioglu et al. 2016), but they also provide important cultural services (Whelan et al. 2008; Gangoso et al. 2013). For these reasons, scavengers have been perceived as beneficial to humans for millennia (Whelan et al. 2008; Moleón et al. 2014). Unfortunately, populations of avian scavengers, and vultures in particular, have diminished worldwide over the last several decades due to nonnatural mortality (Koenig 2006; Ogada et al. 2012).

Another very important and widespread factor contributing to population decreases is the loss of traditional livestock farming practices leading to a diminishing number of carcasses available for scavengers (Donázar et al. 1996, 2009a; Olea and Mateo-Tomás 2009). This reduction may be, in turn, accentuated by the dissociation between farmers and ecosystems with a loss of local ecological knowledge (i.e., the cumulative body of knowledge, practices, and beliefs regarding the relationships of living things to their environment, hereafter, LEK; Díaz et al. 2015), and a lower appreciation of ecosystem services provided by scavengers (Morales-Reyes et al. 2018a). This may hinder conservation efforts against harmful practices like indirect poisoning with baits aimed to kill predators and the use of veterinary drugs that are highly toxic to vultures feeding upon carcasses of medicated animals (Margalida et al. 2013, 2014).

Here, we investigated whether Canarian Egyptian vultures (Neophron percnopterus majorensis) are acknowledged by local farmers as ESPs. We then assessed whether farmers are aware of the presence and abundance of vultures foraging on their properties while disentangling factors influencing these perceptions. For the latter, we took advantage of two different studies: (1) one about the use of farms by GPS-tagged vultures and (2) another about the knowledge of this use by farmers on these farms. The study was conducted on Fuerteventura, where a population of this globally endangered species still survives (Birdlife International 2017). There, Egyptian vultures rely on traditional goat farming under a mix of intensive and extensive regimes (Gangoso et al. 2006). Livestock practices, however, are progressively intensifying so that small traditional farms are disappearing while large farms with mechanized systems are becoming more frequent (García-Martínez et al. 2009). Within this scenario, we specifically predict that the probability of matching farmers' LEK and foraging patterns of GPS-tagged vultures would be greater in (1) older or more experienced farmers, because presumably both lead to higher LEK (Gómez-Baggethun et al. 2010; Oteros-Rozas et al. 2013), (2) male compared to female farmers since it has been found that men are associated with a higher LEK in Mediterranean Europe (Oteros-Rozas et al. 2013), (3) larger farms (greater numbers of livestock) because of a greater availability of carcasses, and (4) farms and their surroundings that are visited by a greater number of vultures.

\section{MATERIALS AND METHODS}

\section{Study area}

The Canary Islands are situated in the northeast Atlantic Ocean, between $27^{\circ} 37^{\prime}$ and $29^{\circ} 25^{\prime} \mathrm{N}$, and $13^{\circ} 20^{\prime}$ and $18^{\circ} 10^{\prime} \mathrm{W}$. Fuerteventura $\left(1659.7 \mathrm{~km}^{2}\right)$ is the most southeasterly island. The landscape is dominated by grass and scrublands with an almost total absence of woodland (Rodríguez Delgado et al. 2000). Agricultural land occupies only $16.75 \%$ of the territory (Molina 2002) of which only $0.3 \%$ is usually cultivated (Cabildo de Fuerteventura 2007). Farming is based on livestock (goats and, to a lesser extent, sheep; Gangoso et al. 2006). From 1970 onward, the number of heads increased from 20000 to 100000 in 2013 but has decreased in recent years (Canarian Government 2017). There were officially 404, 345, and 301 owners of goats and/or sheep in 2013, 2014, and 2015, respectively. Unlike in other Spanish regions, carcass disposal remains banned in the Canary Islands because of sanitary regulations imposed by the European Union after the outbreak of bovine spongiform encephalopathy in 2001 (Donázar et al. 2009b). Officially, remains resulting from natural death and sacrifices of the oldest animals are regularly collected by a specialized company and buried in a garbage dump. Farmers pay an insurance to cover such carcass-collecting service. However, field observations and farmers themselves revealed that carcasses are often abandoned despite the ban (García-Alfonso; unpublished data). However, information on carcass disposal is scarce because farmers are usually reticent to provide details on this illegal practice (see "Results" section).

As there are no large scavenger species, such as griffon vultures, on the island, abandoned carcasses usually last 
several days in the field until total consumption. Moreover, Egyptian vultures may feed on old small remnants scattered across the disposal sites (authors' persl. obs.), so their presence on the farms is not restricted to the day on which carcasses are disposed.

\section{Study species and basic population monitoring}

The Canarian Egyptian vulture is an endemic subspecies inhabiting the eastern islands of the archipelago, where it is sedentary. It is a medium-sized vulture (around $2.5 \mathrm{~kg}$ ) nesting in cliff cavities of variable size. Breeding pairs are territorial but large aggregations of birds may be found at communal roosts and feeding places such as garbage dumps, artificial feeding stations and livestock farms (Cramp and Simmons 1980; Donázar 1993, 2004). This vulture feeds on carcasses of small- and medium-sized animals that are shared with the other three endemic subspecies of facultative scavengers: common buzzards (Buteo buteo insularum), common ravens (Corvus corax canariensis), and yellow-legged gulls (Larus michahellis atlantis) (see García-Heras et al. 2013). The species significantly declined during the twentieth century due to the incidence of nonnatural mortality - mainly accidents with power lines and indirect poisoning (Donázar et al. 2002; Gangoso and Palacios 2002; Gangoso et al. 2009). Currently, the Canarian Egyptian vulture survives only in Fuerteventura and Lanzarote with the bulk of the population concentrated in the former (Agudo et al. 2010). Similar negative population trends are found worldwide, and consequently, the species is considered as globally "endangered" (Birdlife International 2017).

Canarian Egyptian vultures have been intensively monitored since 1998. Territories are regularly visited to determine population size and breeding success, with 54 breeding pairs found in Fuerteventura and 5 in Lanzarote in 2014. Moreover, known locations often used for communal roosting at night (mainly power lines, see Donázar et al. 2002) are also regularly monitored. Intensive marking schemes (metal and plastic rings) have resulted in about $90 \%$ of the population being individually identifiable as of 2014.

\section{Vulture capture and tagging}

From June 2013 to September 2015, we trapped 46 Canarian Egyptian vultures (22 males and 24 females, ages of which ranged from fledgling to 14 years old) with cannon-nets and tagged them with solar-powered GPS transmitters. This represents $16 \%$ of the current population. Two types of GPS devices were used: 26 individuals were equipped with UvA-BiTS (Bouten et al. 2013), and 19 with E-obs devices (GmbH, Munich, Germany). Another individual successively carried a device of each class. Both types of devices have multiple onboard sensors providing geographical coordinates, altitude, speed, and tridimensional movements of each individual according to a defined time interval. For the first-tagged vultures $(n=22$, Table S1), the time interval between locations varied from $3 \mathrm{~s}$ to 20 min due to initial tests of the devices. From 2015 onward, all devices were programmed with time intervals between 1 and $5 \mathrm{~min}$.

Devices were attached as backpacks using 0.84 and $1.12 \mathrm{~cm}$ wide Teflon harnesses. Total system weight was between $31 \mathrm{~g}$ (UvA-BiTS) and $54 \mathrm{~g}$ (E-obs), about $1.4-2.4 \%$ of the mean body mass, respectively, which is below the limit recommended by previous studies to avoid negative effects (3\%, Sergio et al. 2015). All procedures were subject to ethical review and were carried out in accordance with the approved guidelines set out by the Bioethics and Animal Welfare Committee (CEEA-EBDCSIC). Vulture trapping and marking were approved by the Canarian Government.

Analyses included a total of 12432333 locations of 46 different vultures collected over 914 days between 1st July 2013 and 31st December 2015 (Fig. S1). Mean ( \pm SD) number of locations per individual was $270268( \pm 351651)$. Number of days with information per individual was 444 ( \pm 364) days (Table S1). We included GPS information from 18 months before to 18 months after the completion of the surveys, to better capture the general behavior of the vulture population.

\section{Use of farms by vultures}

Since carcasses resulting from the activity of the farms were not discharged at the farm buildings but rather in their vicinity, we first calculated the mean dumping distance from the buildings to the disposal sites. We tried to obtain such information through phone calls $(n=122$, GarcíaAlfonso unpublished data), but only 10 farmers were willing to reveal where they left the carcasses. We extrapolated this information (mean distance $286 \mathrm{~m}, 95 \%$ confidence interval $180-393 \mathrm{~m}$ ) to all farms surveyed ("Local ecological knowledge" section). We used these lower and upper confidence limits to establish two buffer areas around the farm buildings and selected all GPS fixes within these distances. Accordingly, two sets of analyses were performed. To determine the presence of vultures foraging at farms, we selected stationary GPS fixes by establishing a maximum altitude of $25 \mathrm{~m}$ and a maximum instantaneous speed of $2 \mathrm{~m} / \mathrm{s}$ (Schlaich et al. 2016; Klaassen et al. 2017). After filtering the dataset, we retained 6472416 stationary locations. 


\section{Local ecological knowledge}

We conducted 59 face-to-face surveys through questionnaires with farmers in July 2014 (Table S2). The sampling strategy was systematically divided into three main stages. First, we randomly selected an initial set of farmers of extensive livestock farming systems from the Spanish General Register of Livestock Farms. Second, we acquired the contact information of farmers from the local sanitary authorities. Third, we conducted the surveys with farmers on or near their farms. The sample size was representative of the total population of farmers in the study area (see Morales-Reyes et al. 2018a for details and Fig. 1). All farmers were informed that their participation was voluntary and anonymous. We used the questionnaire to collect information regarding two topics: (i) perception of the capacity of Canarian Egyptian vultures to provide ecosystem services relative to the other three scavenger species (buzzards, ravens, and gulls), and (ii) farmers' awareness of the presence and the number of Canarian Egyptian vultures in his/her farm or its surroundings.

First, to evaluate the farmers' perceptions about the capacity of Egyptian vultures and the other scavengers to provide ecosystem services, according to Morales-Reyes et al. (2018a) we used two variables: (1) ESP index average farmer's perception of each one of the four avian scavenger species habitually found at carcasses. We used a five-point scale from very harmful to very beneficial, asking the

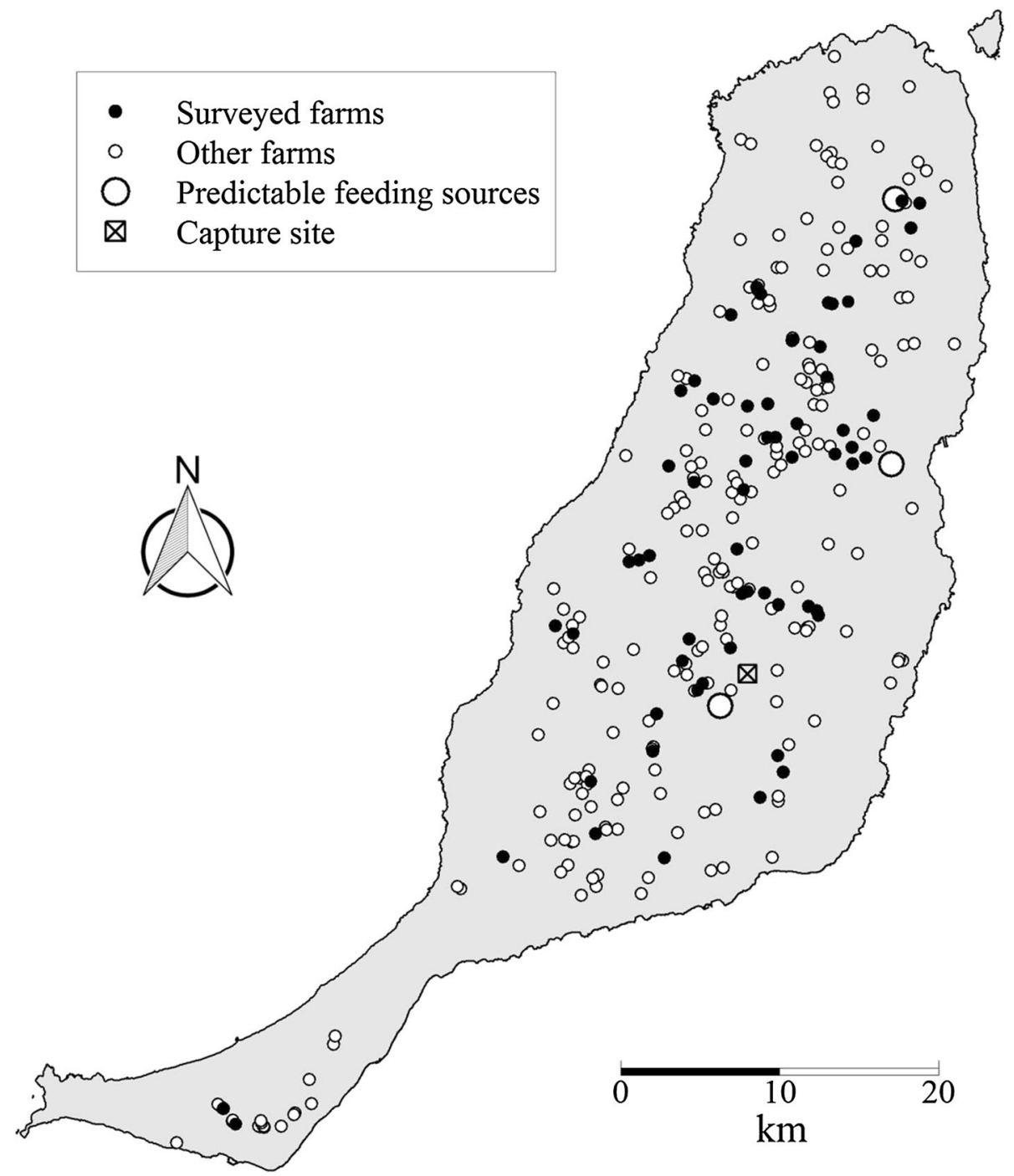

Fig. 1 Spatial information used for studying farmer's perception of vultures and awareness of their presence in Fuerteventura as contrasted with information provided by GPS-tagged birds. Surveyed farms: location of farms where the 59 face-to-face surveys were done. Other farms: location of nonsurveyed farms with goats and/or sheep in Fuerteventura between 2013 and 2015. Predictable feeding sources: location of the three more predictable places in terms of food for vultures. Capture site: location of the cannon net used for capturing vultures and tagging them with GPS devices 
respondents to explain their answers $(n=59)$, (2) Scavenging services (\%) percentage of farmers that selected each species as a provider of scavenging services (i.e., carcass consumption) either in the first, second or third ranking of importance $(n=59)$.

Secondly, to determine factors influencing the consistency between farmers' awareness of the Egyptian vulture presence and GPS data, we used the following information from the surveys: (1) occurrence of vultures perceived by farmers on their farms $(n=55),(2)$ number of goats and sheep on the farms $(n=55)$, (3) number of vultures detected simultaneously by farmers on their farms ( $n=22$ ), and (4) period of the day (i.e., morning, midday, and/or afternoon) when vultures were observed by farmers on their farms $(n=21)$. Farmers' answers were considered as a representation of their global experience on farms in the medium-term instead of specific observations in a specific period of time (see Table S3 for specific questions answered).

\section{Statistical analyses}

We used the Kruskal-Wallis test $(\alpha=0.05)$ to identify differences in farmers' perceptions of the capacity of avian species to provide ecosystem services (ESP index), and Pearson's $\chi^{2}$ test $(\alpha=0.05)$ to determine differences in the perception of species as providers of scavenging services in particular [Scavenging services (\%)].

For determining factors influencing consistency between awareness of vulture occurrence and GPS data, we selected three response variables: (1) The presence of vultures (Presence). Awareness was considered consistent (value $=1$ ) when the response of the farmers matched the GPS data (i.e., farmers answered that they detected vultures and there was at least one GPS location associated with their farms, or that farmers did not detect vultures and no GPS locations were associated with their farms); and inconsistent for the other two possibilities (value $=0$ ). (2) Period of the day with the presence of vultures (TimeSlots). Awareness was considered consistent (value $=1$ ) when farmers answered that they detected the presence of vultures at a certain time of day (morning, midday, and/or afternoon), and there was at least one GPS location associated with their farm during this time period, or that they did not detect vultures and there were no GPS locations; and inconsistent for the other two possibilities (value $=0$ ). (3) The number of vultures perceived by the farmers at their farms (Number). We used the mean value when the farmer gave a range of numbers of vultures.

The explanatory variables were divided into four groups (Table 1): (1) four variables representing vulture behavior (i.e., vulture visits), (2) three associated with farmers, (3) one associated with time, and (4) eight related to characteristics of the farms. Before modeling, collinearity
Table 1 Explanatory variables used to analyze farmers' perceptions about Canarian Egyptian vultures in Fuerteventura. Four sets of models were performed using two response variables: Presence and TimeSlots, calculated according to two radii 180 and $393 \mathrm{~m}$. All variables where initially included in model performing except Hour used just in TimeSlots models

\begin{tabular}{|c|c|}
\hline Variables & Description \\
\hline \multicolumn{2}{|l|}{ Vulture visits } \\
\hline Num days ${ }^{\mathrm{a}}$ & $\begin{array}{l}\text { Number of days with at least one position of } \\
\text { vultures associated with the farm }\end{array}$ \\
\hline Max indvs simult ${ }^{\mathrm{a}}$ & $\begin{array}{l}\text { Maximum number of vultures detected at the } \\
\text { same time in the farm }\end{array}$ \\
\hline Max indvs day ${ }^{a}$ & $\begin{array}{l}\text { Maximum number of different vultures } \\
\text { detected per day in the farm }\end{array}$ \\
\hline Max indvs month ${ }^{\mathrm{a}}$ & $\begin{array}{l}\text { Maximum number of different vultures } \\
\text { detected per month in the farm }\end{array}$ \\
\hline \multicolumn{2}{|l|}{ Farmer } \\
\hline Gender & Gender of the surveyed farmer \\
\hline Age & Age of the surveyed farmer (years) \\
\hline Experience & Number of years working as a farmer \\
\hline \multicolumn{2}{|l|}{ Time } \\
\hline Hour & $\begin{array}{l}\text { Division of the day in morning (sunrise-12:00), } \\
\text { midday (12:00-16:00) and afternoon (16:00- } \\
\text { sunset). Times were selected according to } \\
\text { popular Spanish delimitation of midday }\end{array}$ \\
\hline
\end{tabular}

Farm

Goat, Sheep ${ }^{\mathrm{b}} \quad$ Number of goats and sheep per farm

Dist Main $\mathrm{AFS}^{\mathrm{c}} \quad$ Distance to the main artificial feeding station (center of the island, $\mathrm{km}$ )

Index $\mathrm{AFS}^{\mathrm{c}} \quad$ Index of connectivity to artificial feeding stations (AFSs) and garbage dump

Index Roost ${ }^{\mathrm{c}} \quad$ Index of connectivity to roosting places

Index Terr ${ }^{\mathrm{c}} \quad$ Index of connectivity to vultures' territories

Dist AFS Distance to the nearest artificial feeding stations (AFSs) or garbage dump (km)

Dist Roost Distance to the nearest roosting place $(\mathrm{km})$

Dist Terr Distance to the nearest vultures' territory $(\mathrm{km})$

${ }^{a}$ Calculated from GPS tracking of the whole day for the probability of the presence (Presence) and of each period of the day for the probability of the presence disaggregated by time slot (TimeSlots)

b Total number of livestock, on the basis of livestock censuses (see Methods)

c Index of connectivity calculated following the formula of Hanski (1998): $S_{i}=\sum_{j \neq i} \exp \left(-\alpha d_{i j}\right) N_{j}$. For distance $d_{i j}$, we used the Euclidean distance in kilometers. $N_{j}$ was only included for Dist Roost (mean number of vultures on each roosting place obtained from field data)

between explanatory variables was tested (Graham 2003). We never included in the same model pairs of variables with a correlation coefficient higher than $10.5 \mid$ (Spearman) or a $p$ value higher than 0.05 (Mann-Whitney $U$ ). All the variables were included in the modeling procedures except for the explanatory variable Hour, which was only fitted to 
the response variable TimeSlots. We standardized all variables (except Gender and Hour) by subtracting the mean of each variable and dividing the resulting value by its standard deviation. Since explanatory variables had a nonnormal distribution, data were analyzed in a generalized linear (mixed) model (GLMM) framework (Bolker et al. 2009). The presence was modeled by means of generalized linear models (GLMs), with binomial error distribution and logit link function. For TimeSlots, we used GLMMs with binomial error distribution and logit link function, where farmer was included as a random factor to avoid pseudo replication since the response variable TimeSlots involved three values per farm (morning, midday, and afternoon). Moreover, the four "vulture visits" variables were calculated for each period of the day.

For each of the two first response variables (i.e., Presence and TimeSlots), we performed two sets of models corresponding to values of explanatory variables ("vulture visits") within the two buffers established by lower and upper limits of the confidence interval of the distances from carcass disposal sites to the farms (180 and $393 \mathrm{~m}$, see above), thus implying a total of four sets of models. Models were fitted with a maximum of four variables simultaneously to avoid overparameterization. The number of candidate models per set differed because collinearity was different for each buffer (Tables S4, S5). Model selection was made on the basis of the Akaike's information criterion corrected for small samples size $\left(\mathrm{AIC}_{\mathrm{c}}\right.$; Sugiura 1978). We discarded models including uninformative parameters, i.e., parameters whose $85 \%$ confidence interval overlapped with 0 (Burnham and Anderson 2002; Arnold 2010). In addition, when top-positioned models were redundant, i.e., two or more models included fixed effects with a similar biological interpretation, only one of them was retained, e.g., the four variables related to vulture visits or connectivity index variables with corresponding distance variables (Table 1). Models differing less than two $\mathrm{AIC}_{\mathrm{c}}$ points from the top-ranked models (i.e., the one with the lowest $\mathrm{AIC}_{\mathrm{c}}$ ) were considered statistically equivalent, and thus model averaging was applied to deal with model selection uncertainty (Burnham and Anderson 2002). We tested for overdispersion and determined the explained deviance in the selected subsets of models.

We used Spearman's correlation to test the relationship between the number of vultures that farmers observed on their farms (Number) and the four "vulture visits" explanatory variables (Table 1).

We used R statistical software (R Core Team 2016) with the stats package for GLM and confidence intervals, lme4 (Bates et al. 2015) for the GLMM analysis, AICcmodavg (Mazerolle 2016) for model ranking and MuMIn for model averaging and for calculating overdispersion and explained deviance in GLMMs (Barton 2016).

\section{RESULTS}

Farmers perceived Egyptian vultures as the most beneficial avian scavengers, followed by common buzzards, yellowlegged gulls, and common ravens (Kruskal-Wallis test, $\chi^{2}=125.7, p<0.001$; Fig. 2a). Reasons given by farmers for considering Egyptian vultures as beneficial $(n=56)$ were: vultures are scavengers $(n=48)$, vultures do not produce damage $(n=2)$, vultures are necessary $(n=1)$, vultures are predators $(n=1)$, and no reason $(n=5)$. Moreover, Egyptian vultures were significantly perceived as the main providers of scavenging services followed by common ravens (Pearson's $\chi^{2}$ test, $\chi^{2}=117.6, p<0.001$; Fig. 2b).

Surveys (see "Local ecological knowledge" section) revealed an average number of 119 (range 2-425) livestock casualties per farm and year, with larger farms showing a higher number of deaths (Spearman's $\rho=0.49, p<0.01$,

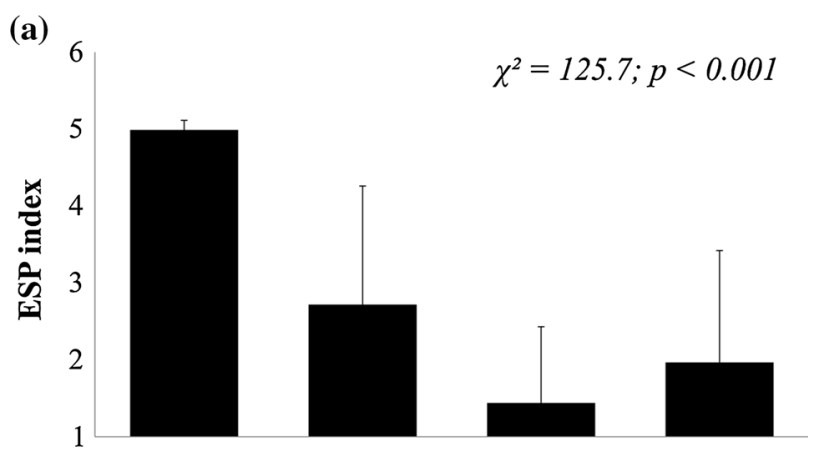

(b)

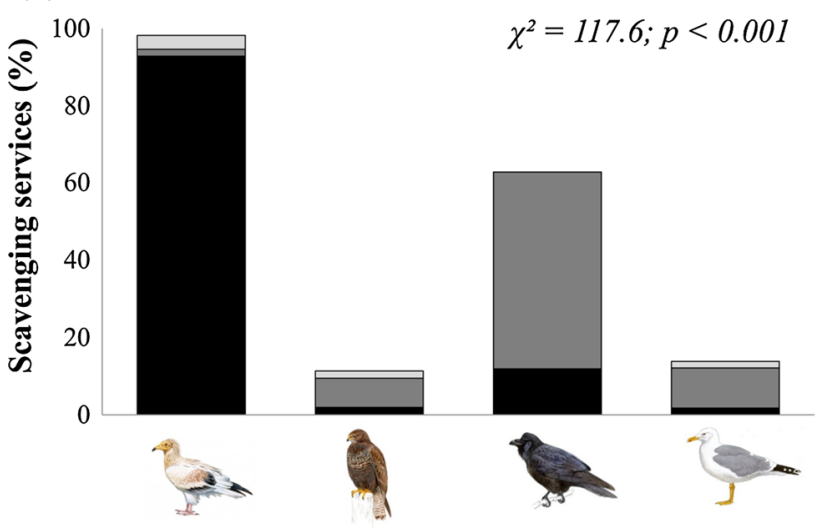

Fig. 2 Perception of capacity of scavenger species to provide scavenging services. a Farmers' perceptions of scavengers as ecosystem services providers (ESP index) by species. Bars and whiskers indicate the mean value of ESP index \pm SD. b Percentage of farmers that perceived the provision of scavenging services [Scavenging services (\%)] by species. The different grade of colors in b show whether these species were ranked first (darkest color), second (middle) or third (lightest) as providers. (Species drawings: (C) Juan Varela, from left to right: Neophron percnopterus majorensis, Buteo buteo insularum, Corvus corax canariensis, and Larus michahellis atlantis) 
$n=50$ ). Farmers indicated whether they abandoned the carcasses always $(n=4)$, sometimes $(n=29)$, or never $(n=25)$. Some farmers also revealed that large farms benefited more from the official carcass-collecting service, to the extent that some owners of small farms indicated that they do not receive this service at all.

Overall, about $60 \%$ of farmers' perceptions about the visits of vultures on their farms were consistent with GPS data (Table 2). In $40 \%$ of the surveys, there was consistency between the presence of GPS-tagged vultures on the farms and positive answers by farmers regarding the occurrence of vultures (Table 2). On the contrary, between 35 and $42 \%$ of them (depending on the radius considered) did not perceive the presence of the birds even though the GPS-tagged vultures certainly visited their farms. Absences of GPS data were always consistent with the farmer's perception of absence (i.e., no farmers indicated that vultures were visiting their farm when no GPS-tagged vultures made visits).

Concerning the consistency of the presence of vultures (Presence), we obtained similar evidence at both spatial scales (180 and $393 \mathrm{~m}$ ): there were both an effect of gender of the farmer and the number of days with visits of vultures (Table S4). Thus, the probability of this consistency was higher for males and for those farms visited more frequently by GPS-tagged vultures (Table 3). Two additional variables were influential at the smallest radius (Table S4): farmers' awareness was more consistent with GPS data for those farms with a smaller number of livestock and located near communal roosts used by vultures at night (Table 3 ; Fig. 3). The percentage of explained deviance was 20.3 and $11.2 \%$ for 180 and $390 \mathrm{~m}$ radii, respectively.

The consistency in awareness in relation to the period of the vulture visits (TimeSlots) decreased from morning to afternoon with the number of livestock at farms and with the distance to communal roosts (Tables 4, S5). Moreover, at $180 \mathrm{~m}$ radius, farmers' responses were more consistent with GPS data for those farms receiving visits of more vultures, while at the $393 \mathrm{~m}$ radius we found an additional

Table 2 Farmers' perceptions in relation to the presence in the farm of GPS-tagged Egyptian vultures. Values represent percentage of farmers' answers $(n=55)$ at two different buffer radii

\begin{tabular}{llll}
\hline Perception & Presence of vultures & \multicolumn{2}{l}{ Radius $(\mathrm{m})$} \\
\cline { 3 - 4 } & & 180 & 393 \\
\hline Yes & Yes & 40 & 40 \\
Yes & No & 0 & 0 \\
No & Yes & 34.5 & 41.8 \\
No & No & 25.5 & 18.2 \\
\hline
\end{tabular}

Table 3 Estimates and standard errors (SEs) resulting from model averaging of selected models of Presence for two radii around the farm. See Table 1 for a full description of each explanatory variable. $85 \%$ Confidence intervals of the estimates are also shown (7.5 and $92.5 \%$ limits). Relative importance (RI) of each variable calculated as sum of the Akaike weights over all of the models in which the term appears. The reference level for factor Gender is 'Male'

\begin{tabular}{lrlrrr}
\hline Variables & Estimates & SE & \multicolumn{1}{l}{$7.5 \%$} & $92.5 \%$ & $\mathrm{RI}$ \\
\hline $\begin{array}{l}\text { Radius } 180 \mathrm{~m} \\
\text { (Intercept) }\end{array}$ & 2.665 & 0.931 & 1.329 & 4.027 & \\
Goat Sheep & -0.001 & 0.001 & -0.002 & 0.000 & 1 \\
Dist Roost & -0.341 & 0.166 & -0.584 & -0.100 & 1 \\
Num days & 0.007 & 0.008 & 0.000 & 0.023 & 0.619 \\
Gender & & & & & 0.619 \\
Gender Female & -1.480 & 1.557 & -4.318 & -0.466 & \\
Radius 393 m & & & & & \\
(Intercept) & 0.007 & 0.337 & -0.480 & 0.493 & \\
Num days & 0.012 & 0.005 & 0.005 & 0.021 & \\
Gender Female & -2.558 & 1.386 & -4.938 & -0.801 & \\
\hline
\end{tabular}

positive relationship with the age of the farmer (Table 4 , Table S5). The percentage of explained deviance was 41.8 and $35.0 \%$ for 180 and $390 \mathrm{~m}$ radii, respectively.

Regarding the number of vultures detected by the farmers (Number), we did not find significant relationships with the four variables measuring "vulture visits" (Spearman's $\rho$ between -0.04 and $0.15 ; p>0.06$ in all the cases).

\section{DISCUSSION}

To our knowledge, this is the first study comparing stakeholder awareness of the presence and abundance of ESPs with highly accurate quantitative field data measuring the spatial distribution of these providers. Since our results revealed that farmers largely perceived the Egyptian vulture as beneficial due to their scavenging habits, this approach helps us understand how stakeholders directly perceive the potential benefit they obtain from the service suppliers. Our findings showed that farmers, who did not receive vulture visits at their farms, never detected their presence, but half of the farmers receiving visits of vultures did not notice them, which could lead to an underestimation of actual services. Some increase in misperceptions when vultures visited the farms was apparent when the buffer of observations around the farm increased (Table 2), which is consistent with a less precise perception of those 


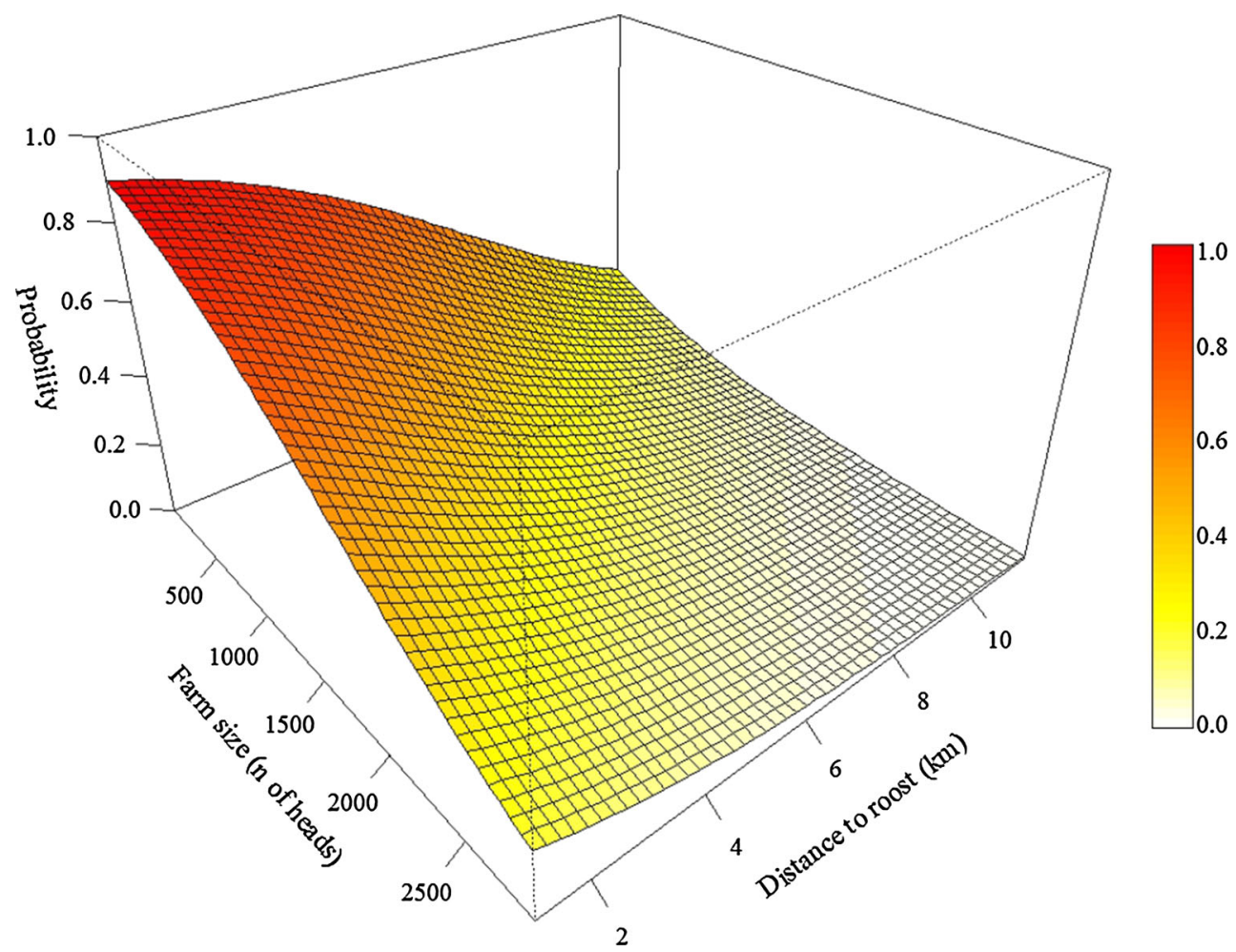

Fig. 3 Effects of farm size (number of goats and sheep: Goat Sheep) and distance to the nearest communal roost (Dist Roost) on the probability of consistency between data of GPS-tagged vultures and farmers' awareness of the presence of Egyptian vultures (Presence) in their farms. We considered $180 \mathrm{~m}$ around the farm as the buffer to determine the presence of GPS-tagged vultures

birds moving outside the activity zone and sight of the farmers.

Since GPS-tagged vultures are only a fraction (15\%) of total vultures inhabiting the island, it could be argued that we obtained only a partial view of the probability of the presence of vultures on the farms. Thus, some farms visited by Egyptian vultures would appear in our analyses as nonvisited, leading to an increase of false absences. Nevertheless, all farmers detecting vultures at their farms received visits of GPS-tagged individuals, which indicates that we achieved a representative sample for the purposes of this study. Additionally, it should be taken into account that we used GPS data recorded in the same period of the surveys to accumulate medium-term data on the occurrence of vultures on the farms. Thus, temporal biases were minimized.

The fact that the vast majority of farmers perceived vultures as highly beneficial and acknowledged their scavenging services is probably due to the persistence in the study area of traditional extensive livestock farming systems (see Morales-Reyes et al. 2018a). In fact, Fuerteventura, along with other oceanic islands, is one of the few places in the world where vultures and human activities are still deeply connected and where cultural ecosystem services associated with the charismatic Egyptian vultures still survive (Gangoso et al. 2006, 2013).
However, misperceptions among farmers receiving vulture visits suggest that the actual benefits received at their holdings are somewhat undervalued. Thus, acquiring informed knowledge on the factors affecting awareness accuracy may be the key to understanding the social dimension of vulture conservation.

The highest consistency between GPS data and farmer awareness of the vulture presence was found in older men, a finding that is likely related to historical and cultural factors. Although we only examined a very specific aspect of LEK, this result would agree with recent studies conducted in rural areas of Spain, that found that men have a higher traditional ecological knowledge than women, and that LEK increases with age (Gómez-Baggethun et al. 2010; Oteros-Rozas et al. 2013). Other studies, however, depicted different scenarios in which women and younger people perceived regulating services (e.g., those provided by vultures through the removal of carcasses) as more important, with provisioning services perceived as more important by men and older people (Martín-López et al. 2012; Briceño et al. 2016). In this sense, it has been shown that regulating services are perceived to a lesser degree than provisioning services, which are more directly detected since they are more readily observable (MA 2005; de Oliveira and Berkes 2014; Muhamad et al. 2014). The apparent contradiction between our results and those of the 
Table 4 Estimates and standard errors (SEs) resulting from model averaging of selected models of TimeSlots for two radiuses around the farm. See Table 1 for a full description of each explanatory variable. $85 \%$ Confidence intervals of the estimates are also shown (7.5 and 92.5\%). Relative importance (RI) of each variable calculated as sum of the Akaike weights over all of the models in which the term appears. The reference level for factor Hour is 'morning'

\begin{tabular}{lrrrrr}
\hline Variables & Estimates & \multicolumn{1}{l}{ SE } & \multicolumn{1}{l}{$7.5 \%$} & $92.5 \%$ & RI \\
\hline Radius 180 m & & & & & \\
$\quad$ Intercept) & 0.386 & 0.544 & -0.407 & 1.180 & \\
Goat Sheep & -0.206 & 0.374 & -1.225 & -0.124 & 0.305 \\
Max indvs day & 0.344 & 0.490 & 0.070 & 1.433 & 0.457 \\
Dist Roost & -0.211 & 0.380 & -1.239 & -0.144 & 0.305 \\
Hour & & & & & 1 \\
Hour midday & 0.702 & 0.741 & -0.378 & 1.783 & \\
Hour afternoon & -1.170 & 0.749 & -2.263 & -0.076 & \\
Radius 393 m & & & & & \\
(Intercept) & 0.861 & 0.569 & 0.031 & 1.691 & \\
Age & 0.154 & 0.302 & 0.006 & 1.017 & 0.301 \\
Goat Sheep & -0.471 & 0.475 & -1.314 & -0.174 & 0.632 \\
Dist Roost & -0.379 & 0.417 & -1.152 & -0.048 & 0.632 \\
Hour & & & & & 1 \\
Hour midday & 0.268 & 0.734 & -0.803 & 1.339 & \\
Hour afternoon & -1.708 & 0.795 & -2.869 & -0.548 & \\
\hline
\end{tabular}

previous research regarding older males perceiving a regulating service, such as carcass removal, more accurately may result from the fact that vultures are easily observable, unlike most regulating services that are intangible (e.g., air purification or climate regulation), and thus they are as detectable by people as a provisioning service (MartínLópez et al. 2012). Moreover, the effect of age could be related to the high abundance of Egyptian vultures in the past (Donázar et al. 2002), and thus older people would be much more familiar with the species and its detection. In the same way, it is also possible that female farmers were less common in the past due to cultural reasons and that this has affected our results. Finally, it cannot be discarded that age and/or sex asymmetries in the time spent by owners on farms may have influenced our results, but unfortunately these data were not available.

As would be expected, farmer awareness about the presence of vultures was more consistent with data from GPS-tracked birds when they frequently visited the farm. Thus, a major presence of vultures, either on the farm or in its surroundings, clearly increases the concordance between farmer perceptions and GPS data. Therefore, adjustment of perception of an ecosystem service to data obtained from GPS-tagged birds seems to depend on the frequency of the service as well as the number of providers.
In the same way, locations of the farms regarding the distribution of vultures over the island influenced farmers' perceptions. Perception was more consistent with GPS data when farms were closer to roosting places, increasing the probability of observing vultures in the surroundings of the farms. Consequently, more contact with vultures, even outside the farms, could imply a greater knowledge and ease of recognition of the species (Roque De Pinho et al. 2014), motivating a major predisposition to recognizing the vulture presence on farms.

More attention should be paid to the negative relationship between farm size and the probability of consistent perception. This result may seem counterintuitive considering our initial prediction of increasing "consistency" because more livestock should imply more carcasses and, consequently, a higher frequency of visits of vultures (Mateo-Tomás and Olea 2010). However, it can be argued that the sanitary regulations imposed by the European Union after the outbreak of bovine spongiform encephalopathy in 2001 may play a role in our results (Donázar et al. 2009b; Margalida et al. 2010; Moleón et al. 2014). Despite the fact that the abandonment of livestock carcasses is still banned in Fuerteventura, some owners of small farms indicated that they rarely or never received carcass collection services. Therefore, the availability of carcasses can certainly be lower on large farms where illegal dumping of large amounts of carrion can be problematic (García-Alfonso unpublished data). Nonetheless, this only partially explains our results because the GPS-tagged vultures still visited large farms without detection by the farmers. Owners of large farms often hire help from outside the family (Navarro-Ríos et al. 2011) and probably spend less time in outdoor activities (including the disposal of carcasses and other livestock remains), which would be carried out by employees. Thus, although some carcasses and remains are probably still abandoned to vultures on large farms, their presence would not be known by the owners. In agreement with this, previous studies have reported that farmers with smaller livestock numbers had a more positive perception of the ecosystem services provided by scavengers (Morales-Reyes et al. 2018a).

Finally, the finding that farmers had an awareness more consistent with GPS data during the morning than during the afternoon may be a reflection of their daily duties, i.e., milking and feeding activities, which are carried out in early hours, while vulture behavior was monitored throughout the day. This suggests that local people perceive the environment at different times compared to scientific studies performed collecting information throughout the day (see Knapp et al. 2013; Morales-Reyes et al. 2018b). 


\section{CONCLUSION}

Because humans are part of ecosystems (Cowling et al. 2008; Olea and Mateo-Tomás 2009), the dissociation between nature and human society may lead to the loss of ecosystem services. Here, we show that LEK of older farmers working on small farms was more consistent with GPS data in relation to the ecosystem services provided by vultures on their property. LEK is important to balance resource use with conservation and manage natural resources sustainably (Eshuis and Stuiver 2005; Knapp et al. 2013). In the Mediterranean area, farmers' LEK and a greater appreciation of ecosystem services is clearly derived from the maintenance of traditional livestock farming practices, such as transhumance (e.g., OterosRozas et al. 2013; Morales-Reyes et al. 2018a), but these practices are disappearing in many regions of the world due to industrialization and globalization. They persist in rural areas but are likely to continue declining (Gómez-Baggethun et al. 2010). In agreement with previous studies in different contexts (Turner and Turner 2008; Gómez-Baggethun et al. 2010; Kai et al. 2014) but contrary to a recent study on farmers' LEK (Morales-Reyes et al. 2018b), our results indicate the deterioration or loss of LEK, apparently associated with the increased farm size and mechanization resulting from the intensification of livestock practices, which is occurring across Europe (García-Martínez et al. 2009). Thus, even if the service providers continue to supply the service, the farmers no longer perceive it as such.

Our results add a new dimension to previous studies claiming the importance of traditional livestock farming practices in the conservation of scavengers (Liberatori and Penteriani 2001; Olea and Mateo-Tomás 2009; MateoTomás and Olea 2010; Morales-Reyes et al. 2018a) and provide evidence of the importance of management of livestock and associated practices from both the farmer and policymaker perspectives.

Our study also shows that the stakeholders' perception of the ecosystem services provided is dependent on the spatial distribution of the population of the providing species, as well as its abundance. A higher frequency of visits and greater proximity to dense population nuclei, such as the communal roosts, where most of the island's population of vultures is concentrated (see Donázar et al. 2002), implied a greater probability of consistency between farmer awareness and data from GPS-tagged vultures. To assess the individual knowledge of stakeholders, it is therefore necessary to incorporate accurate information about the distribution and abundance of the species as well as on the movement of individuals. This result not only presents interesting perspectives to explain why there are strong local asymmetries among stakeholders' perceptions receiving apparently similar ecosystem services (MoralesReyes et al. 2018a), but could have other important implications. Despite perceiving vultures as beneficial due to their scavenging behavior, half of the farmers were not aware of receiving the service, and thus a decline in animal populations, along with a disconnection from nature presumably resulting from the loss of traditional practices, could change perceptions in the long-term toward a misperception of their benefits.

In summary, our findings indicate that studies aimed at understanding how the local community perceives animals operating as ESPs should include multiple dimensions. While personal features of stakeholders, such as gender or age, are widely recognized as important aspects, other sociocultural factors associated with changes in traditional practices and the resulting loss of LEK are less understood. Our study highlights the potential role of modern livestock husbandry in disconnecting people from the benefits provided by wild animals, and how all of these aspects act in concert with the distribution, abundance, and frequency of the ESP itself, such that the service may be even more underappreciated for scarce or threatened organisms.

Acknowledgements We thank Manuel de la Riva, Julio Roldan, Walo Moreno, Margarita Yécora, Isabel Baños, and Juan Ramírez for their help with fieldwork, and Mathijs van Overveld for helpful comments. Funding was provided by the Dirección general de Protección de la Naturaleza (Viceconsejería de Medio Ambiente, Gobierno de Canarias), the Spanish Ministry of Economy and Competitiveness and EU/FEDER (projects CGL2012-40013-C02-02 and CGL2015-66966-C2-1-R), the Severo Ochoa Excellence Award from the Ministerio de Economía y Competitividad (SEV-2012-0262) and ENDESA (Convenio EBD(CSIC)-ENDESA). Z.M.-R and M.G.-A were supported respectively by a pre-doctoral grant (FPU12/00823) and a contract from "Programa de FPU del Ministerio de Educación, Cultura y Deporte" (FPU13/05429).

\section{REFERENCES}

Agudo, R., C. Rico, C. Vilà, F. Hiraldo, and J.A. Donázar. 2010. The role of humans in the diversification of a threatened island raptor. BMC Evolutionary Biology 10: 384. https://doi.org/10.1186/ 1471-2148-10-384.

Allen, J.A. 1893. Our hawks and owls in their relation to agriculture. Auk 10: 199-201.

Arnold, T.W. 2010. Uninformative parameters and model selection using Akaike's information criterion. Journal of Wildlife Management 74: 1175-1178. https://doi.org/10.2193/2009-367.

Ban, N.C., M. Mills, J. Tam, C.C. Hicks, S. Klain, N. Stoeckl, M.C. Bottrill, J. Levine, R.L. Pressey, T. Satterfield, and K.M.A. Chan. 2013. A social-ecological approach to conservation planning: Embedding social considerations. Frontiers in Ecology and the Environment 11: 194-202. https://doi.org/10.1890/ 110205.

Barton, K. 2016. MuMIn: Multi-model inference. $R$ package version 1.15.6. 
Bates, D., M. Maechler, B. Bolker, and S. Walker. 2015. Fitting linear mixed-effects models using lme4. Journal of Statistical Software 67: 1-48. https://doi.org/10.18637/jss.v067.i01.

Bennett, N.J., R. Roth, S.C. Klain, K.M.A. Chan, D.A. Clark, G. Cullman, G. Epstein, M.P. Nelson, R. Stedman, T.L. Teel, R.E.W. Thomas, C. Wyborn, D. Curran, A. Greenberg, J. Sandlos, and D. Veríssimo. 2016. Mainstreaming the social sciences in conservation. Conservation Biology 31: 56-66. https://doi.org/10.1111/cobi.12788.

Birdlife International. 2017. Neophron percnopterus (amended version published in 2016). The IUCN Red List of Threatened Species 2017: e.T22695180A112123458. www.iucnredlist.org. Accessed 05 July 2017.

Bolker, B.M., M.E. Brooks, C.J. Clark, S.W. Geange, J.R. Poulsen, M.H.H. Stevens, and J.S.S. White. 2009. Generalized linear mixed models: A practical guide for ecology and evolution. Trends in Ecology and Evolution 24: 127-135. https://doi.org/10. 1016/j.tree.2008.10.008

Bouten, W., E.W. Baaij, J. Shamoun-Baranes, and K.C.J. Camphuysen. 2013. A flexible GPS tracking system for studying bird behaviour at multiple scales. Journal of Ornithology 154: 571-580. https://doi.org/10.1007/s10336-012-0908-1.

Briceño, J., V. Iñiguez-Gallardo, and F. Ravera. 2016. Factors influencing the perception of ecosystem services in Ecuadorian tropical dry forests. Ecosistemas 25: 46-58. https://doi.org/10. 7818/ecos.2016.25-2.06.

Burnham, K.P., and D.R. Anderson. 2002. Model selection and multimodel inference: A practical information-theoretic approach. Ecological modelling, 2nd edn. New York: Springer. https://doi.org/10.1016/j.ecolmodel.2003.11.004.

Cabildo de Fuerteventura. 2007. Anuario estadístico Fuerteventura. www.slideshare.es. Accessed 27 Feb 2015.

Canarian Government. 2017. Estadística ganadera (www document). http://www.gobiernodecanarias.org/istac/. Accessed 10 Oct 2017.

Cowling, R.M., B. Egoh, A.T. Knight, P.J. O'Farrell, B. Reyers, M. Rouget, D.J. Roux, A. Welz, and A. Wilhelm-Rechman. 2008. An operational model for mainstreaming ecosystem services for implementation. Proceedings of the National Academy of Sciences of USA 105: 9483-9488. https://doi.org/10.1073/pnas. 0706559105

Cramp, S., and K.E.L. Simmons. 1980. The birds of the Western Palearctic, vol. II. Oxford: Oxford University Press.

de Oliveira, L.E.C., and F. Berkes. 2014. What value São Pedro's procession? Ecosystem services from local people's perceptions. Ecological Economics 107: 114-121. https://doi.org/10.1016/j. ecolecon.2014.08.008

Díaz, S., S. Demissew, J. Carabias, C. Joly, M. Lonsdale, N. Ash, A. Larigauderie, J.R. Adhikari, et al. 2015. The IPBES Conceptual Framework-Connecting nature and people. Current Opinion in Environmental Sustainability 14: 1-16. https://doi.org/10.1016/j. cosust.2014.11.002

Donázar, J.A. 1993. Los buitres ibéricos. Madrid: Biología y conservación.

Donázar, J.A. 2004. Alimoche Común Neophron percnopterus. Madrid: Libro Rojo de las Aves de España. A. Madroño.

Donázar, J.A., A. Margalida, and D. Campión. 2009a. Vultures, feeding stations and sanitary legislation: A conflict and its consequences from the perspective of conservation biology, Munibe 29. ed. Aranzadi. Donostia, San Sembastián: Society of Sciences.

Donázar, J.A., M.A. Naveso, J.L. Tella, and D. Campión. 1996. Extensive grazing and raptors in Spain. In Bird conservation and farming policy in Europe, ed. D.J. Pain and M.W. Pienkowski, 117-149. Cambridge: Cambridge University Press.
Donázar, J.A., C.J. Palacios, L. Gangoso, O. Ceballos, M.J. Gonzáles, and F. Hiraldo. 2002. Conservation status and limiting factors in the endangered population of Egyptian vulture (Neophron percnopterus) in the Canary Islands. Biological Conservation 107: 89-97.

Donázar, J.A., A. Margalida, M. Carrete, and J.A. Sánchez-Zapata. 2009b. Too sanitary for vultures. Science 326: 664. https://doi. org/10.1126/science.326_664a.

Eshuis, J., and M. Stuiver. 2005. Learning in context through conflict and alignment: Farmers and scientists in search of sustainable agriculture. Agriculture and Human Values 22: 137-148. https:// doi.org/10.1007/s10460-004-8274-0.

Everard, M., D. Khandal, and Y.K. Sahu. 2017. Ecosystem service enhancement for the alleviation of wildlife-human conflicts in the Aravalli Hills, Rajasthan, India. Ecosystem Services 24: 213-222. https://doi.org/10.1016/j.ecoser.2017.03.005.

Gangoso, L., and C.J. Palacios. 2002. Endangered Egyptian vulture (Neophron percnopterus) entangled in a power line ground-wire stabilizer. Journal of Raptor Research 36: 238-239.

Gangoso, L., J.A. Donázar, S. Scholz, C.J. Palacios, and F. Hiraldo. 2006. Contradiction in conservation of island ecosystems: Plants, introduced herbivores and avian scavengers in the Canary Islands. Biodiversity and Conservation 15: 2231-2248. https:// doi.org/10.1007/s10531-004-7181-4.

Gangoso, L., P. Alvarez-Lloret, A.A.B. Rodríguez-Navarro, R. Mateo, F. Hiraldo, and J.A. Donázar. 2009. Long-term effects of lead poisoning on bone mineralization in vultures exposed to ammunition sources. Environmental Pollution 157: 569-574. https://doi.org/10.1016/j.envpol.2008.09.015.

Gangoso, L., R. Agudo, J.D. Anadón, M. de la Riva, A.S. Suleyman, R. Porter, and J.A. Donázar. 2013. Reinventing mutualism between humans and wild fauna: Insights from vultures as ecosystem services providers. Conservation Letters 6: 172-179. https://doi.org/10.1111/j.1755-263x.2012.00289.x.

García-Heras, M.-S., A. Cortés-Avizanda, and J.A. Donázar. 2013. Who are we feeding? Asymmetric individual use of surplus food resources in an insular population of the endangered Egyptian vulture Neophron percnopterus. PLoS ONE 8: e80523. https:// doi.org/10.1371/journal.pone.0080523.

García-Martínez, A., A. Olaizola, and A. Bernués. 2009. Trajectories of evolution and drivers of change in European mountain cattle farming systems. Animal 3: 152-165. https://doi.org/10.1017/ s1751731108003297.

Gómez-Baggethun, E., S. Mingorría, V. Reyes-García, L. Calvet, and C. Montes. 2010. Traditional ecological knowledge trends in the transition to a market economy: Empirical study in the Doñana natural areas. Conservation Biology 24: 721-729. https://doi.org/ 10.1111/j.1523-1739.2009.01401.x.

Graham, M.H. 2003. Statistical confronting multicollinearity in ecological. Ecology 84: 2809-2815.

Hanski, I., 1998. Metapopulation dynamics. Nature 396: 41-49. https://doi.org/10.1038/23876.

Hartter, J., J. Solomon, S.J. Ryan, S.K. Jacobson, and A. Goldman. 2014. Contrasting perceptions of ecosystem services of an African forest park. Environmental Conservation 41: 330-340. https://doi.org/10.1017/s0376892914000071.

Kai, Z., T.S. Woan, L. Jie, E. Goodale, K. Kitajima, R. Bagchi, and R.D. Harrison. 2014. Shifting baselines on a tropical forest frontier: Extirpations drive declines in local ecological knowledge. PLOS ONE. https://doi.org/10.1371/journal.pone. 0086598.

Klaassen, R.H.G., A.E. Schlaich, W. Bouten, and B.J. Koks. 2017. Migrating Montagu's harriers frequently interrupt daily flights in both Europe and Africa. Journal of Avian Biology 48: 180-190. https://doi.org/10.1111/jav.01362. 
Knapp, C.N., J. Cochran, F.S. Chapin, G. Kofinas, and N. Sayre. 2013. Putting local knowledge and context to work for Gunnison sage-grouse conservation. Human-Wildlife Interaction 7: 195-213.

Koenig, R. 2006. Vulture research soars as the scavengers' numbers decline. Science 312: 1591-1592.

Kremen, C. 2005. Managing ecosystem services: What do we need to know about their ecology? Ecology Letters 8: 468-479. https:// doi.org/10.1111/j.1461-0248.2005.00751.x.

Lewan, L., and T. Söderqvist. 2002. Knowledge and recognition of ecosystem services among the general public in a drainage basin in Scania, Southern Sweden. Ecological Economics 42: 459-467.

Liberatori, F., and V. Penteriani. 2001. A long-term analysis of the declining population of the Egyptian vulture in the Italian Peninsula: Distribution, habitat preference, productivity and conservation implications. Biological Conservation 101: 381-389. https://doi.org/10.1016/s0006-3207(01)00086-6.

Luck, G.W., R. Harrington, P.A. Harrison, C. Kremen, P.M. Berry, R. Bugter, T.P. Dawson, F. De Bello, S. Díaz, C.K. Feld, J.R. Haslett, D. Hering, A. Kontogianni, S. Lavorel, M. Rounsevell, M.J. Samways, L. Sandin, J. Settele, M.T. Sykes, S. Van Den Hove, M. Vandewalle, and M. Zobel. 2009. Quantifying the contribution of organisms to the provision of ecosystem services. BioOne 59: 223-235. https://doi.org/10.1025/bio.2009.59.3.7.

Margalida, A., J.A. Donázar, M. Carrete, and J.A. Sánchez-Zapata. 2010. Sanitary versus environmental policies: Fitting together two pieces of the puzzle of European vulture conservation. Journal of Applied Ecology 47: 931-935. https://doi.org/10. 1111/j.1365-2664.2010.01835.x.

Margalida, A., R. Arlettaz, and J.A. Donázar. 2013. Lead ammunition and illegal poisoning: Further international agreements are needed to preserve vultures and the crucial sanitary service they provide. Environmental Science and Technology 47: 5522-5523. https://doi.org/10.1021/es401544j.

Margalida, A., J.A. Sánchez-Zapata, G. Blanco, F. Hiraldo, and J.A. Donázar. 2014. Diclofenac approval as a threat to Spanish vultures. Conservation Biology 28: 631-632. https://doi.org/10. 1111/cobi.12271.

Martín-López, B., and C. Montes. 2015. Restoring the human capacity for conserving biodiversity: A social-ecological approach. Sustainability Science 10: 699-706. https://doi.org/ 10.1007/s11625-014-0283-3

Martín-López, B., I. Iniesta-Arandia, M. García-Llorente, I. Palomo, I. Casado-Arzuaga, D.G. Del Amo, E. Gómez-Baggethun, E. Oteros-Rozas, I. Palacios-Agundez, B. Willaarts, J.A. González, F. Santos-Martín, M. Onaindia, C.A. López-Santiago, and C. Montes. 2012. Uncovering ecosystem service bundles through social preferences. PLOS ONE 7: e38970. https://doi.org/10. 1371/journal.pone.0038970.

Mateo-Tomás, P., and P.P. Olea. 2010. Diagnosing the causes of territory abandonment by the Endangered Egyptian vulture Neophron percnopterus: The importance of traditional pastoralism and regional conservation. Oryx 44: 424-433. https://doi. org/10.1017/s0030605310000189.

Mazerolle, M.J. 2016. Model selection and multimodel inference based on $(Q) A I C_{(c)}$. R package version 2.0-4.

Millennium Ecosystem Assessment (MA). 2005. Ecosystems and human well-being: Synthesis. Washington, DC: Island Press.

Moleón, M., J.A. Sanchez-Zapata, A. Margalida, M. Carrete, N. Owen-Smith, and J.A. Donázar. 2014. Humans and scavengers: The evolution of interactions and ecosystem services. BioScience 64: 394-403. https://doi.org/10.1093/biosci/biu034.

Molina, A.C.P. 2002. El sistema de cultivo en gavias de Fuerteventura. In Antología Sobre Pequeño Riego, ed. J.P. Viqueira, Vol. III, 161-193. Sistemas de Riego No Convencionales.
Morales-Reyes, Z., J.M. Pérez-García, M. Moleón, F. Botella, M. Carrete, C. Lazcano, R. Moreno-Opo, A. Margalida, J.A. Donázar, and J.A. Sánchez-Zapata. 2015. Supplanting ecosystem services provided by scavengers raises greenhouse gas emissions. Scientific Reports 5: 7811. https://doi.org/10.1038/ srep07811.

Morales-Reyes, Z., B. Martín-López, M. Moleón, P. Mateo-Tomás, F. Botella, A. Margalida, J.A. Donázar, G. Blanco, I. Pérez, and J.A. Sánchez-Zapata. 2018a. Farmer perceptions of the ecosystem services provided by scavengers: What, who, and to whom. Conservation Letters 11: e12392. https://doi.org/10.1111/conl. 12392.

Morales-Reyes, Z., B. Martín-López, M. Moleón, P. Mateo-Tomás, P.P. Olea, E. Arrondo, J.A. Donázar, and J.A. Sánchez-Zapata. 2018b. Shepherds' local knowledge and scientific data on the scavenging ecosystem service: Insights for conservation. Ambio. https://doi.org/10.1007/s13280-018-1055-6.

Morgan-Brown, T., S.K. Jacobson, K. Wald, and B. Child. 2010. Quantitative assessment of a Tanzanian integrated conservation and development project involving butterfly farming. Conservation Biology 24: 563-572. https://doi.org/10.1111/j.1523-1739. 2009.01433.x.

Muhamad, D., S. Okubo, K. Harashina, B. Gunawan, and K. Takeuchi. 2014. Living close to forests enhances people's perception of ecosystem services in a forest-agricultural landscape of West Java, Indonesia. Ecosystem Services 8: 197-206. https://doi.org/10.1016/j.ecoser.2014.04.003.

Navarro-Ríos, M.J., G. Fernández, and R. Perezgrovas. 2011. Characterization of Majorera goat production systems in the Canary Islands. In Economic, social and environmental sustainability in sheep and goat production systems (Options Méditerranéennes: Série A. S'meniraires Méditerranéens; n. 100), eds. A. Bernués, J.P. Boutonnet, I. Casasús, M. Chentouf, D. Gabiña, M. Joy, A. López-Francos, P. Morand-Fehr, F. Pacheco, 205-210. Zaragoza: CIHEAM/FAO/CITA-DGA.

Ogada, D.L., F. Keesing, and M.Z. Virani. 2012. Dropping dead: Causes and consequences of vulture population declines worldwide. Annals of the New York Academy of Sciences 1249: 57-71. https://doi.org/10.1111/j.1749-6632.2011.06293.x.

Olea, P.P., and P. Mateo-Tomás. 2009. The role of traditional farming practices in ecosystem conservation: The case of transhumance and vultures. Biological Conservation 142: 1844-1853. https:// doi.org/10.1016/j.biocon.2009.03.024.

Oteros-Rozas, E., R. Ontillera-Sánchez, P. Sanosa, E. GómezBaggethun, V. Reyes-García, and J.A. González. 2013. Traditional ecological knowledge among transhumant pastoralists in Mediterranean Spain. Ecology and Society 18: 33. https://doi. org/10.5751/es-05597-180333.

Pfeiffer, M.B., J.A. Venter, and C.T. Downs. 2015. Identifying anthropogenic threats to Cape Vultures Gyps coprotheres using community perceptions in communal farmland, Eastern Cape Province, South Africa. Bird Conservation International 25: 353-365. https://doi.org/10.1017/s0959270914000148.

$\mathrm{R}$ Core Team. 2016. $R$ : A language and environment for statistical computing. Vienna: R Found. Stat. Comput.

Rodríguez Delgado, O., A. García Gallo, and J.A. Reyes Betancort. 2000. Estudio fitosociológico de la vegetación actual de Fuerteventura (Islas Canarias). VIERAEA 28: 61-98.

Roque De Pinho, J., C. Grilo, R.B. Boone, K.A. Galvin, and J.G. Snodgrass. 2014. Influence of aesthetic appreciation of wildlife species on attitudes towards their conservation in Kenyan agropastoralist communities. PLOS ONE 9: 1-10. https://doi. org/10.1371/journal.pone.0088842.

Schlaich, A.E., R.H.G. Klaassen, W. Bouten, V. Bretagnolle, B.J. Koks, A. Villers, C. Both, and J. Gill. 2016. How individual 
Montagu's Harriers cope with Moreau's Paradox during the Sahelian winter. Journal of Animal Ecology 85: 1491-1501. https://doi.org/10.1111/1365-2656.12583.

Sekercioglu, C.H., D.G. Wenny, and C.J. Whelan. 2016. Why birds matter: Avian ecological function and ecosystem services. Journal of Field Ornithology. https://doi.org/10.1111/jofo.12214.

Sergio, F., G. Tavecchia, A. Tanferna, L. López Jiménez, J. Blas, R. De Stephanis, T.A. Marchant, N. Kumar, and F. Hiraldo. 2015. No effect of satellite tagging on survival, recruitment, longevity, productivity and social dominance of a raptor, and the provisioning and condition of its offspring. Journal of Applied Ecology 52: 1665-1675. https://doi.org/10.1111/1365-2664. 12520 .

Sugiura, N. 1978. Further analysis of the data by Akaike's information criterion and the finite corrections. Communications in Statistics: Theory and Methods 7: 13-26. https://doi.org/10. 1080/03610927808827599.

Turner, N.J., and K.L. Turner. 2008. "Where our women used to get the food": Cumulative effects and loss of ethnobotanical knowledge and practice; case study from coastal British Columbia. Botany 86: 103-115. https://doi.org/10.1139/b07-020.

Whelan, C.J., D.G. Wenny, and R.J. Marquis. 2008. Ecosystem services provided by birds. Annals of the New York Academy of Sciences 1134: 25-60. https://doi.org/10.1196/annals.1439.003.

Wilson, E.E., and E.M. Wolkovich. 2011. Scavenging: How carnivores and carrion structure communities. Trends in Ecology and Evolution 26: 129-135. https://doi.org/10.1016/j.tree.2010.12. 011.

\section{AUTHOR BIOGRAPHIES}

Marina García-Alfonso $(\square)$ is a PhD Student at the Doñana Biological Station (CSIC). Her research interests include spatial ecology and behavior of vultures.

Address: Department of Conservation Biology, Estación Biológica de Doñana (CSIC), C/Américo Vespucio 26, 41092 Seville, Spain.

e-mail: margaralf@gmail.com

Zebensui Morales-Reyes is a PhD Student at the Miguel Hernández University. His research interests include ecology of scavengers, the assessment of ecosystem services, stakeholder analysis, and conservation biology.
Address: Department of Applied Biology, Miguel Hernández University, Avda. de la Universidad, s/n, 03202 Elche, Spain. e-mail: zmorales@umh.es

Laura Gangoso is a Marie-Curie Postdoctoral Fellowship at the University of Amsterdam. Her research interests include behavioral ecology, biotic interactions, and conservation biology.

Address: Institute for Biodiversity and Ecosystem Dynamics, University of Amsterdam, Science Park 904, 1098 XH Amsterdam, The Netherlands.

e-mail: laurag@ebd.csic.es

Willem Bouten is a Professor of Computational Geo-ecology at the University of Amsterdam. His research interests include movement ecology, eScience, and modeling.

Address: Institute for Biodiversity and Ecosystem Dynamics, University of Amsterdam, Science Park 904, 1098 XH Amsterdam, The Netherlands.

e-mail: W.Bouten@uva.nl

José A. Sánchez-Zapata is a Professor at the Miguel Hernández University. His research interests include biodiversity, conservation Biology, and ecology and evolution.

Address: Department of Applied Biology, Miguel Hernández University, Avda. de la Universidad, s/n, 03202 Elche, Spain. e-mail: toni.sanchezzapata@gmail.com

David Serrano is a Tenured Scientist at the Doñana Biological Station (CSIC). His research interests include ecology, evolution, behavior, and wildlife conservation.

Address: Department of Conservation Biology, Estación Biológica de Doñana (CSIC), C/Américo Vespucio 26, 41092 Seville, Spain.

e-mail: serrano@ebd.csic.es

José A. Donázar is a Professor of Research at the Doñana Biological Station (CSIC). His research interests include population and conservation ecology of long-lived vertebrates, in particular birds of prey and among them, large body-sized scavengers.

Address: Department of Conservation Biology, Estación Biológica de Doñana (CSIC), C/Américo Vespucio 26, 41092 Seville, Spain.

e-mail: donazar@ebd.csic.es 